\title{
DISPERSAL ACTIVITIES OF THE BLACK-TAILED \\ PRAIRIE DOG IN WIND CAVE NATIONAL PARK
}

\author{
Monte Garrett \\ William L. Franklin \\ Department of Animal Ecology \\ lowa State University
}

\section{Objectives}

The population of black-tailed prairie dogs (Cynomys ludovicianus) in Wind Cave National Park has been rapidly expanding since periodic poisoning programs were discontinued in the mid-1960s. This population increase is alarming to park resource managers because: 1) the native prairie component of the park is shrinking every year due to encroachment of forest and modification by prairiedogs; 2 ) the loss of productive range is believed to be reducing the park's capacity to support other wildlife species; and 3) the park is being accused by local landowners of being a reservoir for prairie dogs infesting adjacent rangeland. Since lethal control measures on these animals have been discouraged (NPS Advisory Board 1980), basic knowledge of prairie dog dispersal is necessary in order to better manage the park's resources.

This study was funded by the National Park Service (Project 2348) and has been conducted from May 1979 to the present time. The primary objectives were 1) to determine conditions within the colony which led to dispersal of prairie dogs, 2) to identify environmental characteristics which favored one area over another for establishment of a new colony, and 3) to test the use of behaviorally based techniques to terminate the occupation of newly inhabited rangelands.

\section{Methods}

Procedures followed for trapping, handling, and marking prairie dogs are described by Hoogland (1977). A recently established prairie dog colony in Wind Cave Canyon was selected as the focal study area. Behavioral data on the study colony were taken from an elevated blind overlooking the colony.

Prairie dogs are territorial and generally restrict all their activities within a well-defined area (King 1955). Territory boundaries were mapped from territorial interactions. Behavioral observations provided baseline data on prairie dog activities. This information was necessary to assess the effectiveness of behavioral techniques of control, and to address social factors relevant to dispersal of prairie dogs. 
Radiotelemetry was employed in order to obtain basic information on prairie dog dispersal (i.e., distances moved, routes followed, and degree of success). Since this technique had not been used previously on prairie dogs, radiocollars were designed especially for this study by Cedar Creek Bioelectronics Lab, Bethel, Minnesota. Prairie dogs observed away from established colonies were considered dispersing individuals. These migrants were captured, collared, and tracked to their destination. Since immigrants to a colony are met with hostility from colony residents (King 1955), all newcomers to the study colony were also captured and collared.

Artificial visual barriers were constructed on the study colony to investigate their effectiveness as a behavioral method of control. These consisted of strips of burlap ( $50 \mathrm{~cm}$ width) affixed with wire to steel stakes. Three barriers were located on the periphery of the colony and positioned perpendicular to the direction of colony expansion. They were arranged radially with the observation blind so that all prairie dog activity was easily observed.

\section{Results}

A small 3-year old colony was located in May 1979 and established as the primary study site. From May 1979 to October 1980, the colony expanded from approximately 0.5 hectare to 1.5 hectares ( $200 \%$ growth). Colony expansion was most dramatic during the summer following the emergence of new litters. Population size increased from 32 individuals in May 1979 to 85 individuals in October 1980 (165\% increase). High animal density and rapid growth seem to be characteristic of newly founded colonies. This may be due to an abundant food supply and available habitat, resulting in high reproductivity (Koford 1958 and this study).

Prairie dogs began dispersing in early May. Maximum sightings occurred during the first two weeks of June. By July, there were no more sightings of dispersing animals. Twelve males and 9 females were found dispersing. Even though there was no difference between the sexes in the likelihood of dispersing, the age of the migrant tended to be predictable. Males were all yearlings while female migrants also included older individuals $\left(x^{2}=11.2, \mathrm{df}=2\right.$, $P<.005)$. This suggests that males and females may disperse for different reasons (see Dobson 1979). Seven radiocollared migrants were tracked from 0.5 to 7.0 kilometers within the park and into adjacent rangeland. Two of these individuals disappeared during tracking; the other 5 arrived to other colonies. Survival probability for an immigrant was not good. At the study colony, immigrants were significantly more likely to be victimized by a predator than was a colony resident $\left(x^{2}=18.1, \mathrm{df}=2, \mathrm{P}<.005\right)$.

The proximate factors responsible for triggering prairie dog dispersal appear to include: 1) lack of access to "edge" of the colony, the preferred feeding area ( $P<.001$ throughout the period of study), which may result in dispersal of individuals in coteries without edge; 2) harassment of adults by the young, which results in adult females tending to move to areas where fewer young are 
residing $\left(x^{2}=7.0, d f=2, P<.01\right)$ (c.f. King 1955); and 3) relatedness of individuals, which results in yearling males tending to disperse away from close genetic relatives $\left(x^{2}=5.79, \mathrm{df}=2 \mathrm{P}<.025\right)$. Due to apparent "incest taboos" (Hoogland 1980, unpublished) a male has little chance of breeding unless he moves away from his natal territory. Further, social subordination of yearling males by the dominant male of the coterie (family group) may trigger some dispersal, but data are insufficient thus far.

Prairie dogs seem to more easily colonize areas that have been subjected to some type of disturbance (e.g., overgrazing, previous cultivation, trampling by ungulates). All of the large colonies in the park have a history of previous disturbance. In addition, over the last 15 years, periods of time in which the ungulate population was extremely high correspond closely to sharp increases in prairie dog colony acreage. Vegetation analyses of new colonies in the Wind Cave NP vicinity suggest that lowered vegetation and bare ground are characteristics of newly colonized areas. However, since new colonies are not usually discovered until after the new inhabitants have somewhat modified the vegetation, it is difficult to separate cause and effect.

It has been suggested that tall vegetation or other such visual obstructions may prevent or inhibit prairie dog colonization (Koford 1958, Smith 1958). An experiment using artificial visual barriers was conducted in an expansion area on the study colony. Over a 2month period, animal activity was reduced $61 \%$ in the area containing visual barriers compared to a $97 \%$ increase in a control area. An expanded visual barrier test will be conducted next year.

\section{Conclusions}

Prairie dog dispersal has been found to be a predictable phenomenon. Movements beginning in late spring may result in individuals of either sex travelling to different locations within the park and onto rangelands adjacent to the park. However, predators take most dispersing prairie dogs and may be instrumental to the natural regulation of these animals. Additional study is needed in order to develop basic knowledge necessary for management of prairie dog dispersal.

Extended analyses of newly colonized areas support the hypothes is that prior disturbance may be a requisite for successful prairie dog colonization. The implications of this relationship must be considered when implementing other park management programs (i.e., bison and elk herd culls, and controlled burning programs). In addition, a cooperative effort between park wildlife managers and private landowners is required in order to manage prairie dogs. Knowledge of those factors that encourage prairie dog colonization and proper land practices will help control numbers of unwanted prairie dogs on private lands adjacent to the park.

The use of visual barriers as a management tool will be substantiated during the next field season. Even though this technique shows 
encouraging results, a material that can withstand prairie dog gnawing without constant maintenance is necessary for application at the management level.

\section{Literature Cited}

Dobson, F. S. 1979. An experimental study of dispersal in the California ground squirrel. Ecol. $60(6): 1103-1109$.

Hoogland, J. L. 1977. The evolution of coloniality in white-tailed and black-tailed prairie dogs (Sciuridae: Cynomys leucurus and $\underline{C}$. ludovicianus). Ph.D. dissertation, Univ. of Michigan.

Hoogland, J. L. 1980. Avoidance of incest in prairie dogs. Dept. of Biology, Princeton Univ. (unpublished).

King, J. A. 1955. Social behavior, social organization and population dynamics in a black-tailed prairie dog town in the Black Hills of South Dakota. Contrib. Lab. Vert. Bio. 67. Univ. of Mich. $126 \mathrm{pp}$.

Koford, C. B. 1958. Prairie dogs, whitefaces, and blue grama. Wildl. Monogr. 3:1-78.

National Park Service Advisory Board. 1980. The prairie dogs on NPS lands. Report from the subcommittee, Badlands Natl. Park Study Team. Wind Cave National Park files.

Smith, R. E. 1958. Natural history of the prairie dog in Kansas. Misc. Publ. No. 16. Mus. of Nat. Hist,, Univ. of Kansas.

Acknowledgements

We wish to thank Superintendent Lester McClanahan and the Wind Cave National Park staff for their help throughout the study. We would especially like to thank Rich Klukas and John Hoogland for their advice and assistance in data collection. 